\title{
Column Supported Embankments with Geosynthetic Encased Columns: Parametric Study
}

\author{
Majid Khabbazian • Christopher L. Meehan • \\ Victor N. Kaliakin
}

Accepted: 26 May 2014 / Published online: 1 July 2014

(C) Springer New York 2014

\begin{abstract}
Three-dimensional finite element analyses were performed to investigate different factors that affect the behavior of column supported embankments (CSEs) that are constructed using geosynthetic encased columns (GECs) as the deep foundation elements. Analyses were performed to study the influence of the geosynthetic encasement on the behavior of granular columns (GCs) in CSEs. Stress reduction ratios (SRRs) obtained from finite element analyses were compared to those calculated from ten different analytical solutions. Parametric analyses were also carried out to study the effect of variations in the stiffness of the encasement, the area replacement ratio, and the length of the geosynthetic encasement on the performance of CSEs. Finally, the sensitivity of the numerical results, particularly the lateral displacement of GECs, to the constitutive model that was used to simulate the behavior of the granular column material was examined. Numerical results showed that encasing a GC in a CSE not only improves the performance of the CSE but also enhances the behavior of the GC. No agreement was found between the calculated values of the SRR from finite element analyses and those from existing analytical solutions.
\end{abstract}

Keywords Geosynthetics · Granular column · Geosynthetic encased column · Unit cell • 3-d finite element analysis

M. Khabbazian

Earth Engineering Incorporated, East Norriton, PA, USA

e-mail: majid@udel.edu

M. Khabbazian • C. L. Meehan • V. N. Kaliakin $(\bowtie)$

Department of Civil and Environmental Engineering, University of Delaware, 301 DuPont Hall, Newark, DE 19716, USA

e-mail: kaliakin@udel.edu

C. L. Meehan

e-mail: cmeehan@udel.edu 


\section{Notation}

a Column diameter/width or pile cap diameter/width (m) (when there is no pile cap, $a$ denotes the column diameter/width; in the case of a pile with a cap, $a$ denotes the cap diameter or width).

$\alpha \quad$ Yield function parameter (dimensionless)

$\beta \quad$ Settlement reduction ratio (dimensionless)

$C$ Hardening parameter (dimensionless)

c Effective cohesion $(\mathrm{Pa})$

$D$ Column diameter (m)

e Void ratio at unit pressure (dimensionless)

$E \quad$ Elastic modulus of encased soil (Pa)

$\phi \quad$ Effective friction angle (degree)

$\eta_{1} \quad$ Failure surface parameter (dimensionless)

$h \quad$ Yield function parameter (dimensionless)

$H \quad$ Height of the embankment (m)

$J \quad$ Tensile modulus (N/m)

$\kappa \quad$ The slope of the swelling line (dimensionless)

$K_{\mathrm{p}} \quad$ Coefficient of passive earth pressure (dimensionless)

$\lambda \quad$ The slope of the virgin consolidation line/elastic modulus exponent (dimensionless)

$\mu \quad$ Plastic potential parameter (dimensionless)

$m \quad$ Failure surface parameter (dimensionless)

$M \quad$ Slope of the critical state line/elastic modulus number (dimensionless)

$\nu \quad$ Poisson's ratio (dimensionless)

$p \quad$ Hardening parameter (dimensionless)

$q \quad$ Surcharge applied to the top of the embankment $(\mathrm{Pa})$

$s \quad$ Center-to-center column/pile cap spacing (m)

$\sigma_{\mathrm{p}} \quad$ Vertical stress on top of the column/pile cap $(\mathrm{Pa})$

$\gamma \quad$ Unit weight of the fill material $\left(\mathrm{N} / \mathrm{m}^{3}\right)$

$\Psi \quad$ Dilation angle (degree)

$\Psi_{2} \quad$ Plastic potential parameter (dimensionless)

\section{Introduction}

Column supported embankments (CSEs) are a ground improvement technique used to overcome bearing capacity failure, large total and differential settlements, lateral spreading, and slope instability of embankments constructed over problematic soils. In recent years, CSEs have increasingly been used in highway or railroad embankments, roadway widening, and bridge approach fills. In CSEs, columns have the important role of transferring the surcharge and embankment loads from the ground surface to a stiffer underlying layer. A wide range of deep foundation systems, utilizing either stiff or non-stiff columns, can be used for CSEs. One of the major advantages of CSEs is that the designer is not limited to any particular column type and has flexibility when selecting the most appropriate column for the site conditions that are encountered. In very soft soils (e.g., those with undrained strengths less than $15 \mathrm{kPa}$ ), the use of granular columns can be problematic due to the lack of required lateral confining pressure, particularly in the upper portion of the column.

Different techniques have been proposed to enhance the performance of granular columns. Aboshi et al. [1] and Sharma et al. [56] reinforced the top portion of each 
granular column with a steel skirt and horizontal layers of geogrid, respectively. Rao and Bhandari [52] reported the use of concrete plugs or cement grout to prevent lateral bulging of the columns. Juran and Riccobono [23] suggested mixing the stone column material that is placed at the top of each column with cement. Another method that can be used to provide the required lateral confining pressure to increase the bearing capacity of granular columns is to encase them with a suitable geosynthetic to form geosynthetic encased columns (GECs).

Improved performance of GECs over conventional granular columns (GCs) has been verified using laboratory test results (e.g., [3, 4, 6, 15, 40, 45, 48, 57, 61, 62]), by numerical analyses [5, 14, 26, 27, 29, 30, 46, 47, 50, 64], and by full-scale load tests (e.g., [65]).

This paper presents the results of three-dimensional (3-d) unit cell finite element analyses that were carried out to investigate the relative importance of different factors that affect the behavior of CSEs constructed using GECs. The improvement that is realized in the response of a CSE through encasing a GC is first investigated. Next, the influence of variations in the geosynthetic stiffness, the area replacement ratio (ARR), and the length of geosynthetic encasement on the performance of CSEs with GECs is studied. Finally, to examine the sensitivity of the numerical results to the constitutive model that is used to simulate the behavior of the encased granular soil, parallel analyses were performed using the Mohr-Coulomb and Single Hardening constitutive models.

\section{Finite Element Modeling}

Before embarking on the aforementioned parametric study of CSEs constructed using GECs, a "base configuration" of this boundary value problem must first be defined. As shown in Fig. 1a, a square spacing pattern for GECs was assumed in the research described herein. For columns in a square pattern with equal center-to-center spacing in both the longitudinal and transverse directions, the unit cell (a single column surrounded by the tributary area of soil) has a square geometry (Fig. 1b). A 3-d finite element analysis is required to properly model this unit cell. Since it has two lines of symmetry (Fig. 1b), only one quarter of the unit cell was modeled in the finite element analyses. An ARR (i.e., the ratio of the area of the column to the total area of a unit cell) of $20 \%$ was selected for the base configuration. Assuming the column diameter to be $0.80 \mathrm{~m}$, the resulting center-to-center spacing of the columns equals $1.60 \mathrm{~m}$ in a square pattern. The height of the embankment and the thickness of the soft soil and columns were both assumed to be $5 \mathrm{~m}$. A rigid layer was assumed to underlie the soft soil and columns. A typical finite element mesh used in the analyses is shown in Fig. 1c. At the bottom boundary of the mesh, the displacements are set to zero in the $z$-direction. On the planes of symmetry, normal displacement is restricted.

The embankment, encased soil columns, and soft surrounding soil were discretized using three-dimensional hexahedral elements. The geosynthetic was represented by membrane elements. For both the embankment and columns, the granular soil was assumed to be loose Sacramento River sand. The granular materials were idealized using an isotropic linear elastic-perfectly plastic model with a Mohr-Coulomb failure criterion. The following Mohr-Coulomb model parameter values were used to 


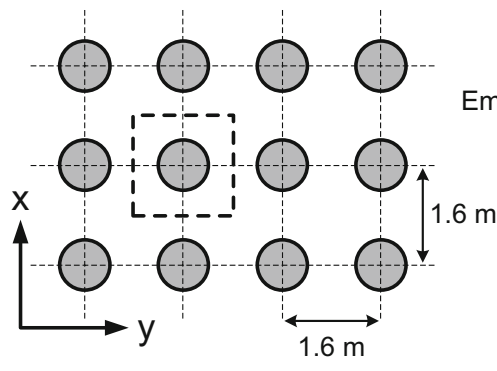

(a) Plan View

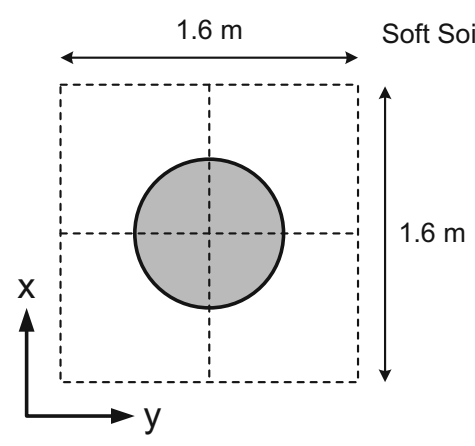

(b)

Unit Cell

(c)

Fig. 1 a Plan view of CSE; $\mathbf{b}$ plan view of unit cell; and $\mathbf{c}$ finite element mesh

characterize the granular materials: an effective friction angle $(\phi)$ equal to $35.0^{\circ}$, an effective cohesion $(c)$ equal to 0.0 , a dilation angle $(\psi)$ of $0.0^{\circ}$, an elastic modulus $(E)$ equal to $30,000 \mathrm{kPa}$, and a Poisson's ratio $(\nu)$ equal to 0.20 . Kaliakin et al. [24] discuss the determination of these values from experimental data for loose Sacramento River sand from tests performed by Lee and Seed [39]. The unit weight of Sacramento River sand was assumed to be $20 \mathrm{kN} / \mathrm{m}^{3}$. It should be noted that the fill material above the columns can play a key role in transferring the embankment loads to the columns. As a result, well-compacted granular materials are usually recommended for the construction of embankments over columns. A detailed study of the influence of the fill material on embankment load transfer is, however, beyond the scope of this paper.

The soft soil was assumed to be normally consolidated Bangkok clay [7], and was idealized using the modified Cam Clay model. Khabbazian et al. [33] investigated the effect of the soft soil constitutive model when numerically modeling CSEs constructed with GECs as the deep foundation elements, and concluded that the use of the modified Cam Clay model is preferable over the Mohr-Coulomb or linear elastic models for accurately capturing the behavior of the soft soil between columns. The specific model parameter values used to characterize the soil were determined by matching numerical model results with experimental data for soft Bangkok clay [7]. This soil classifies as a fat clay $(\mathrm{CH})$, with a specific gravity $\left(G_{\mathrm{s}}\right)$ of 2.72 , a liquid limit $(\mathrm{LL})$ of $118 \pm 2 \%$, a plastic limit (PL) of $43 \pm 2 \%$, and a plasticity index (PI) of $75 \pm 4 \%$. The following Cam clay model parameter values were used to characterize the Bangkok clay: the slope of the swelling and re-compression line $(\kappa)$ was equal to 0.09 , the slope of the virgin 
consolidation line $(\lambda)$ was equal to 0.51 , the slope of the critical state line $(M)$ was equal to 1.0 , the void ratio $(e)$ at a unit pressure of $1 \mathrm{kPa}$ was equal to 2.0 , and a Poisson's ratio $(\nu)$ of 0.3 was assumed. Finally, the unit weight of Bangkok clay was assumed to be $20 \mathrm{kN} / \mathrm{m}^{3}$.

The geosynthetic was assumed to be an isotropic linear elastic material with a Poisson's ratio of 0.3 (e.g., [41, 47]). Alexiew et al. [2] documented that design values of the encasement tensile modulus $(J)$ between 2,000 and $4,000 \mathrm{kN} / \mathrm{m}$ were required for the geosynthetic used to encase granular columns on a number of different projects ( $J$ is also commonly referred to as the geosynthetic stiffness, e.g., [47]). Consequently, a value of $J=3,000 \mathrm{kN} / \mathrm{m}$ was used in the numerical simulation of the geosynthetic encasement in the base configuration. The thickness of the geosynthetic $(t)$ was assumed to be $2 \mathrm{~mm}$ for all of the numerical analyses that were performed. Khabbazian et al. [28] and Khabbazian [27] indicated that using an isotropic linear elastic material that is capable of carrying both compressive and tensile stresses for encasement can increase the bearing capacity of GECs and adversely affect the shape of lateral displacement (bulging) of GECs. To properly account for the fact that the geosynthetic does not carry compressive loads, a "No Compression" option was used in the finite element analyses. This ensured that spurious compressive forces would not be predicted in the geosynthetic reinforcement. In all of the finite element analyses that were performed herein, no interface elements were used between the geosynthetic and the surrounding soils. This assumption is consistent with the modeling approach that has been used by a variety of other researchers in this area (e.g., [42, 47, 63]).

All finite element analyses were performed using the program ABAQUS [19]. The finite element analyses were initiated by activating the initial stresses in the GECs and in the surrounding soft soil. The initial lateral earth pressure was assumed to be at an "at-rest" condition. The lateral earth pressure coefficient $(K)$ was determined to be 0.5 , using the empirical relationship proposed by Brooker and Ireland [9]; i.e., $K_{\mathrm{o}}=0.95-\sin$ $\phi$. Initial deformations due to assignment of gravity to foundation soils were minimized by predefining vertical and lateral earth pressures within the elements of GECs and soft soil before activation of in situ stresses. After establishing the initial stress state, the embankment construction was simulated in a number of steps. The embankment loading was modeled by progressively assigning gravity to each $0.5 \mathrm{~m}$ thick layer of elements in the embankment. In all of the analyses, the excess pore pressures were assumed to have dissipated over time, i.e., the analyses were considered to be drained.

\section{Influence of Encasement on the Performance of Granular Columns in a Column Supported Embankment}

The use of GCs in very soft soils can be problematic due to the lack of adequate lateral confining pressure, particularly in the upper portion of the column. This typically serves as the prime motivation for using GECs, which tend to have a significantly improved strength and stress-displacement response over GCs when they are used in very soft foundation soils (e.g., [29, 30]). In order to better understand the influence that encasing a GC has on the performance of a CSE, the "base" CSE configuration case was analyzed using both unencased columns (GCs) and encased columns (GECs), using the 3-d unit cell idealization. 
Figure 2 presents the average vertical stresses carried by both a GEC and GC versus the height of the embankment. For a given height, it is clear that the load transferred to the GEC is always greater than that transferred to the GC; this difference increases with the height of embankment. For example, for an embankment height equal to $1.0 \mathrm{~m}$, the average vertical stress on top of the GEC is 1.3 times the comparable value carried by the GC. This ratio becomes 1.7 when the height of the embankment reaches $5.0 \mathrm{~m}$. This is in agreement with the findings of others (e.g., [2, 4, 5, 29, 30, 48]), who have shown that using a high-strength geosynthetic can significantly enhance the load-displacement response of granular columns; the encasement effectively makes the GC into a stiffer deep foundation element.

Since more stresses from the embankment are transferred to a GEC than to a GC, the surrounding soft soil in a CSE with GECs carries less vertical stresses than the soft soil below a CSE with GCs. This reduced stress level corresponds to smaller vertical displacements (settlements) in the soft foundation soil around a GEC than around a GC (Fig. 3). It is clear from Fig. 3 that substantially less vertical displacement of the soft soil occurs when GECs are used in place of comparably sized GCs. For example, for a 5-m embankment height, the finite element analyses indicate that the final maximum settlement of the soft soil in the case of the GEC is approximately $33 \mathrm{~cm}$. This maximum settlement increases to $63 \mathrm{~cm}$ if traditional GCs are used in place of the GECs. These results help to quantify the benefits of geosynthetic encasement for granular columns that are used as part of a CSE system. In particular, the enhanced column stiffness that results from encasement significantly reduces the embankment settlement that occurs by improving the load transfer behavior to the underlying stiff foundation layer.

Also shown in Fig. 3 is the settlement of untreated soft soil (i.e., the original soft soil without columns) subjected to the embankment loads. It is evident that the inclusion of either GCs or GECs can significantly reduce the settlement of the soft soil.

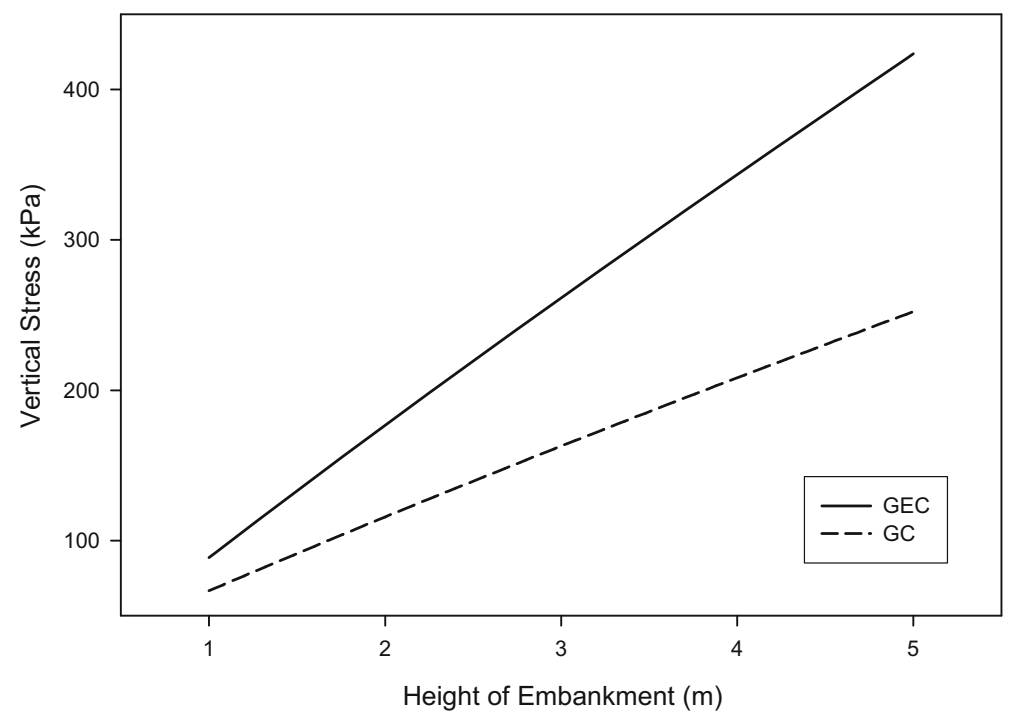

Fig. 2 Comparison of average vertical stress carried by a GEC and GC in a CSE of varying height 


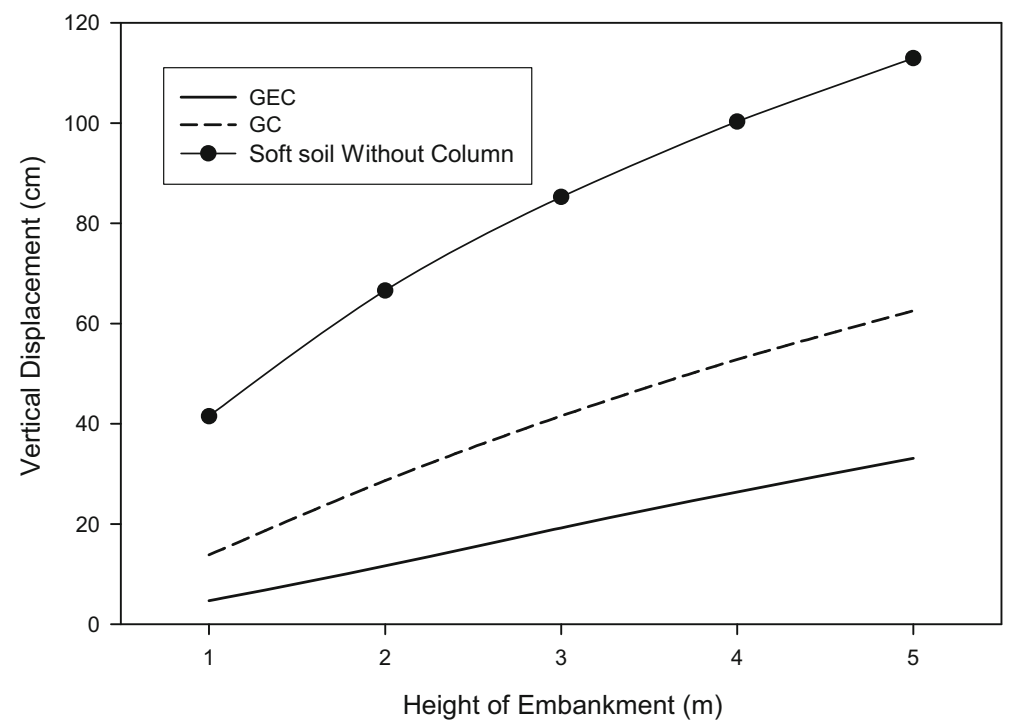

Fig. 3 Effect of geosynthetic encasement on the settlement of the soft soil

\section{Effect on Settlement Reduction Ratio}

To better illustrate the degree of improvement in the soft soil that is realized through the use of any type of ground improvement technique, a parameter called the settlement reduction ratio $(\beta)$ is commonly used. The settlement reduction ratio is defined as the ratio of the settlement of the treated soil to the settlement of untreated soil [8]. The lower the value of $\beta$, the better the performance that has been realized due to ground improvement. Figure 4 presents the variations of $\beta$ with embankment height for the soft soil that is improved by a GEC and a GC. The superior improvement that is achieved by the former over the latter is evident, as the settlement reduction ratio in the case of the GEC is consistently lower than that for the case of the GC. In particular, for an embankment height of $1.0 \mathrm{~m}$ the value of $\beta$ associated with the GEC is 0.11 , while the comparable value for the $\mathrm{GC}$ is 0.33 . For an embankment height of $5.0 \mathrm{~m}$, the values of $\beta$ for CSEs with GECs and GCs increase to 0.29 and 0.55 , respectively.

\section{Effect on Stress Reduction Ratio}

The stress reduction ratio (SRR), which is defined as the ratio of the average stresses on the soft soil to the average stresses applied by the embankment, is an important parameter in the design of CSEs. It has been observed that there is little agreement between existing analytical methods that are used to calculate the SRR (e.g., [20, 49, 58]). In addition, no guidelines are available for the selection of a method that yields the most realistic SRR values. The Appendix lists a series of equations that have been proposed to date by a variety of researchers to calculate the SRR beneath a CSE. Figure 5 presents a comparison of SRR values obtained using these equations with those obtained from 3-d unit cell finite element analyses of CSEs involving both a GEC and a GC. Also shown in this figure are the geometric averages of the respective analytical SRR values. The following observations are made from Fig. 5: 


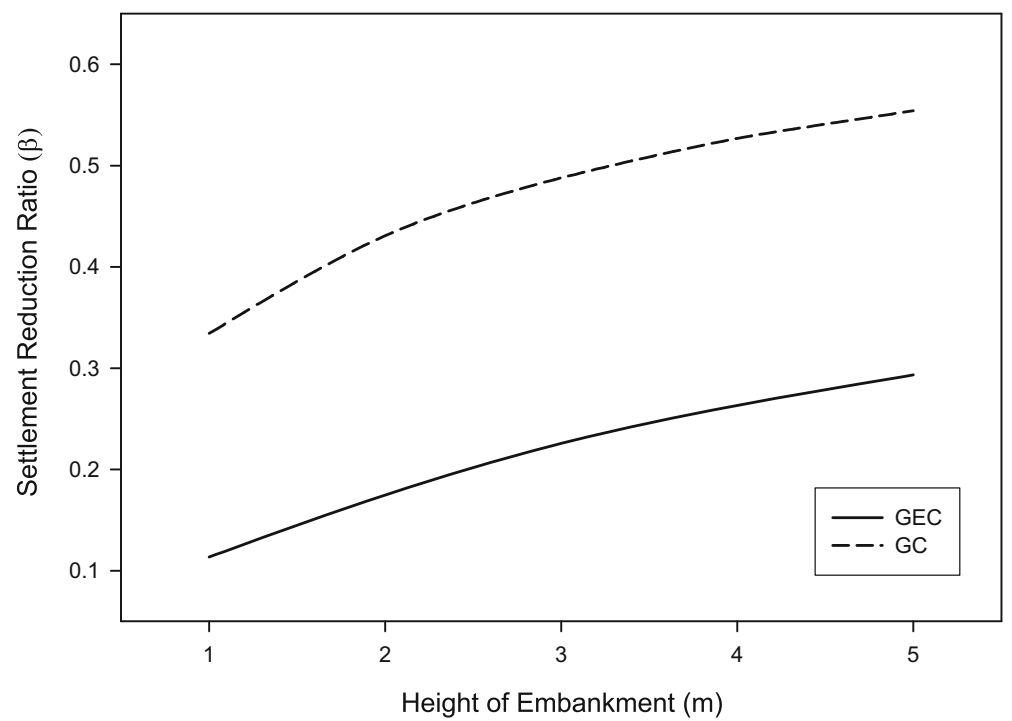

Fig. 4 Effect of geosynthetic encasement on the settlement reduction ratio $(\beta)$

- For the case of a CSE with a GEC, the SRR is significantly lower than in the case of a CSE with a GC.

- In the finite element analyses, the SRR increases with the height of the embankment. Conversely, the analytically computed SRR values become smaller with increases in the embankment height. This can be explained by the fact that the analytical solutions are primarily developed for CSEs with rigid piles. CSEs with

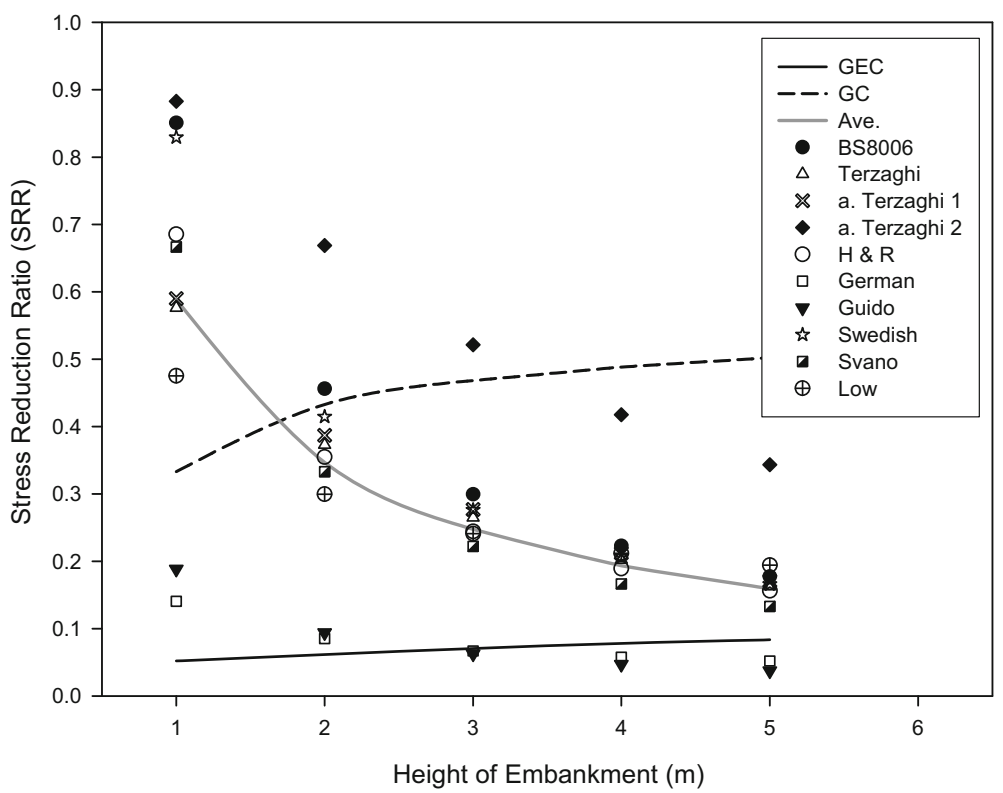

Fig. 5 Comparison of SRR values calculated from analytical solutions and 3-d unit cell finite element analyses 
rigid piles experience much larger values of differential settlement between the columns and the soft surrounding soil than what is experienced by CSEs with either GCs or GECs. As a result, in CSEs with GECs, the "arching effect," which plays a key role in transferring embankment loads to the columns, is not as noticeable as in CSEs constructed with rigid piles. Furthermore, as the stiffness difference is greater between rigid piles and the surrounding soft soil than it is between GECs and the surrounding soft soil, more vertical stresses from the embankment material tend to be transferred to the rigid piles than to the GECs.

- The average SRR from the analytical solutions is not in agreement with the results of the finite element analyses. For CSEs with GECs, the analytical solutions tend to significantly overestimate the value of SRR; however, for the case of GCs, they can significantly underestimate the SRR, particularly at the higher embankment heights.

- Among the ten different analytical methods that were studied, the Guido et al. [16] and German methods yield the closest SRR values to those obtained from finite element analysis of the GEC. These two methods show the maximum difference with the SRR calculated from finite element analysis of GCs (except for at an embankment height of $1.0 \mathrm{~m}$ ).

- The disparity among the analytical solutions diminishes as the height of the embankment increases.

- Except for the adapted Terzaghi 2, Guido et al. [16], and German methods, all the other analytical solutions yielded SRR values that were fairly close to the geometric average values from all of the methods.

\section{Effect on Lateral Displacement}

Figure 6 shows the lateral displacements of the GEC and GC when the height of the embankment is $5.0 \mathrm{~m}$. As expected, the GC experiences excessive lateral displacement at the top portion of the column (i.e., up to a depth of about $1.0 \mathrm{~m}$ ), after which the lateral displacement gradually decreases. In the case of the GEC, the lateral displacement is more uniform throughout the column. It should be noted that the stresses carried by the GEC are significantly greater than those in the GC (Fig. 2), but the lateral displacement of the GC is always greater than that for GEC. From Figs. 3 and 6, it is clear that the use of a high-strength geosynthetic for confinement not only increases the strength of a granular column but also prevents lateral displacement of the column material into the soft surrounding soil. From Fig. 6, it is also evident that the simulated lateral displacement of the GEC is somewhat oscillatory along the length of the column. This phenomenon does not have a physical explanation but, instead, is a manifestation of the material model used in the finite element analysis to characterize the encased soil in the GEC. A more detailed explanation of this phenomenon is presented in a subsequent section of this paper.

\section{Parametric Study}

In order to investigate the influence of variations in a number of the input parameters on the behavior of CSEs with GECs, a series of parametric analyses were next performed. 


\section{Lateral Displacement $(\mathrm{mm})$}

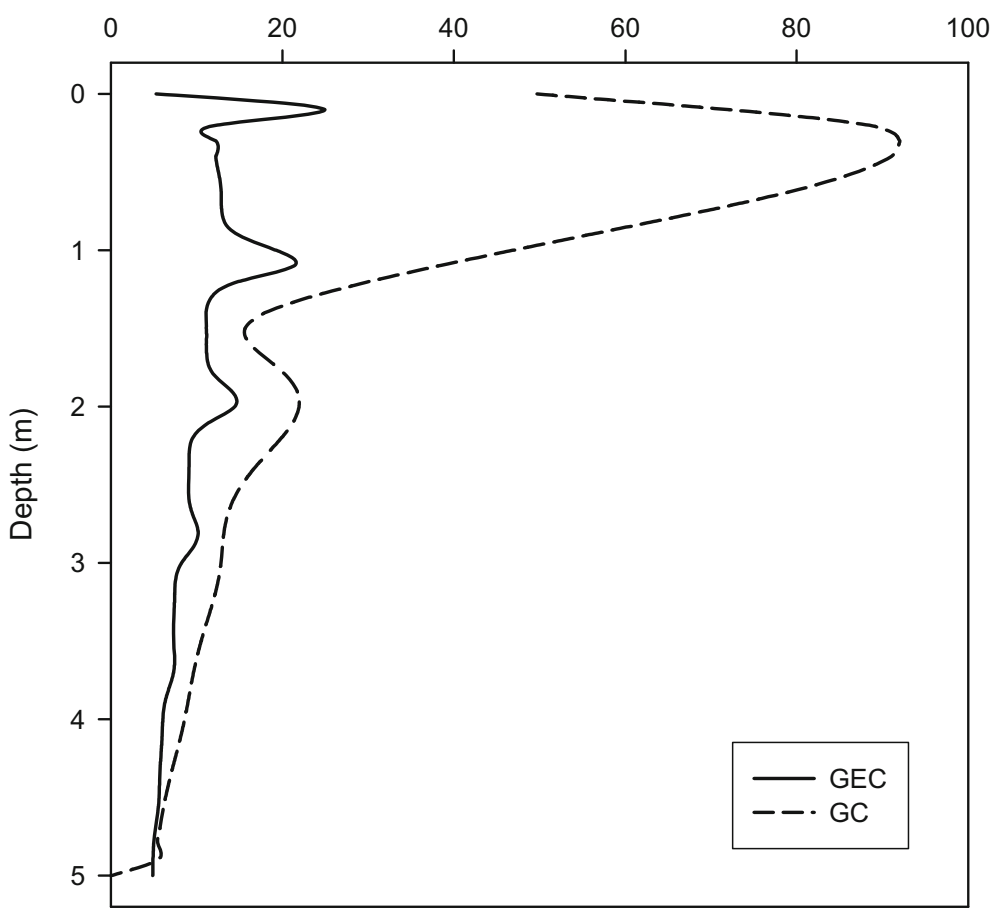

Fig. 6 Influence of geosynthetic encasement on the lateral displacement of granular columns

In these analyses, the value of a single parameter was changed from the "base" configuration; as this was done, all of the other parameters were kept unchanged from their "base" values. For interested readers, it is timely to note here that Khabbazian et al. [29] present a parametric study of factors that affect the performance of a singly loaded GEC, of the type that could be used for foundation-support applications.

\section{Effect of Geosynthetic Encasement Stiffness}

As discussed previously, the effect of column stiffness has a significant impact on the overall performance of a CSE system. By increasing the stiffness of the geosynthetic encasement in the GECs, it is possible to improve the overall stiffness of the GECs and consequently to improve the performance of the CSE. The influence of the GECs' geosynthetic encasement stiffness on the overall performance of the CSEs was studied by varying the GEC encasement stiffness from $J=1,000 \mathrm{kN} / \mathrm{m}$ to $J=10,000 \mathrm{kN} / \mathrm{m}$ (recall that the "base" value of $J$ was $3,000 \mathrm{kN} / \mathrm{m}$ ). The variation of settlement reduction ratios $(\beta)$ versus embankment height for GECs with varying encasement stiffness is shown in Fig. 7. For reference, the variation of $\beta$ for the case of a GC is also shown in this figure. Not surprisingly, as the stiffness of the geosynthetic encasement increases, $\beta$ decreases, indicating improved performance of the CSE. The degree of improvement increases with the height of the embankment. For example, as the encasement stiffness increases from 1,000 to $10,000 \mathrm{kN} / \mathrm{m}$, the settlement reduction ratio decreases by 24 and $36 \%$ for embankment heights equal to 1.0 and $5.0 \mathrm{~m}$, respectively. 


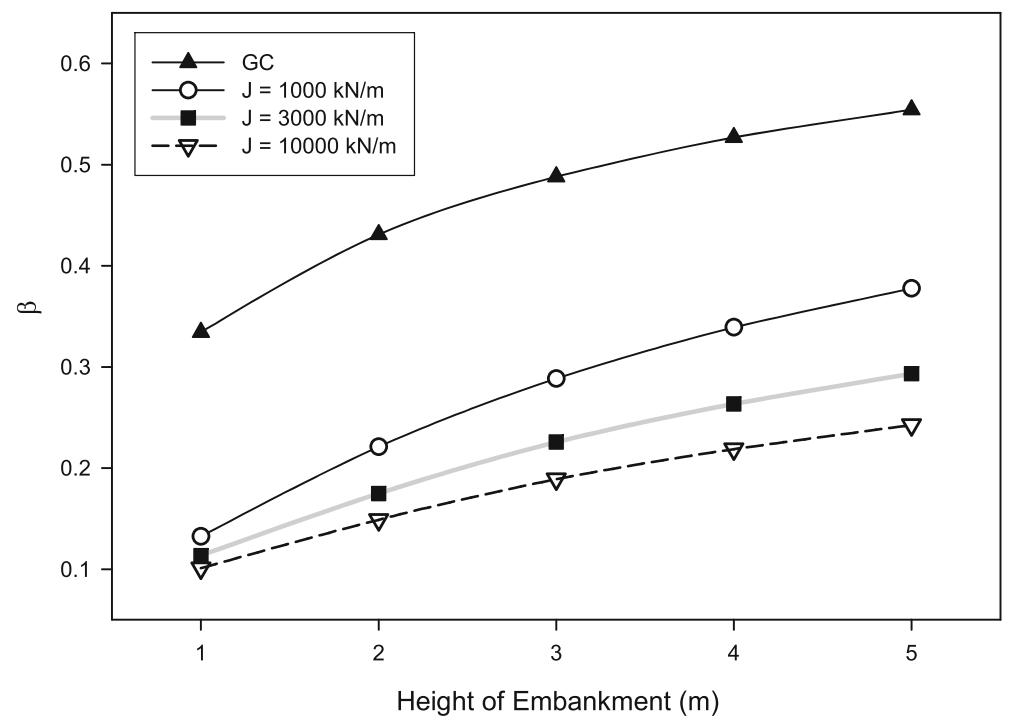

Fig. 7 Effect of encasement stiffness on the settlement reduction ratio $(\beta)$

Figure 8 shows the effect that variations in $J$ have on the lateral displacement of GECs for an embankment height equal to $5.0 \mathrm{~m}$. For reference, the response associated with a GC is also shown in this figure. As $J$ increases, the lateral displacement of the GEC decreases. It is also clear from Fig. 8 that even encasement with a relatively low value of $J$ can significantly reduce the lateral displacement of GCs.

\section{Influence of Area Replacement Ratio on the Performance of CSEs}

As noted previously, the ARR is the ratio of the area of a column to the total area of the corresponding unit cell. Collin [13] stated that the ARR should be selected to be between 10 and $20 \%$ for the preliminary design of CSEs. Han et al. [17] reported that the ARR for GRCSEs mostly ranged from 5 to $30 \%$. To investigate the effect that variations in the ARR have on CSE response, three CSEs were modeled with ARR values equal to 10,20 , and $30 \%$. During these analyses, all other parameters were maintained at their "base" values.

Figure 9 shows the average stresses transferred to the top of the GECs for the various ARRs that were examined. As the ARR decreases (i.e., as the center-to-center spacing of the GECs increases), the embankment load carried by an individual GEC increases. This is logical, as there are fewer columns available to support the total load that is applied by a given embankment. The difference between the vertical stresses at the top of GECs with varying ARRs increases with the height of embankment. It is also clear from Fig. 9 that the difference between CSEs with ARRs of 10 and $20 \%$ is greater than that for CSEs with ARRs of 20 and $30 \%$. For example, for an embankment height of $5.0 \mathrm{~m}$, as the ARR decreases from 30 to $20 \%$, the average stress carried by the GEC increases by $38 \%$. However, as the ARR decreases from 20 to $10 \%$, the load carried by the GEC increases by $52 \%$.

The influence of variations in the ARR on the performance of CSEs can be more easily observed by examining the settlement reduction ratios $(\beta)$ that result from these 


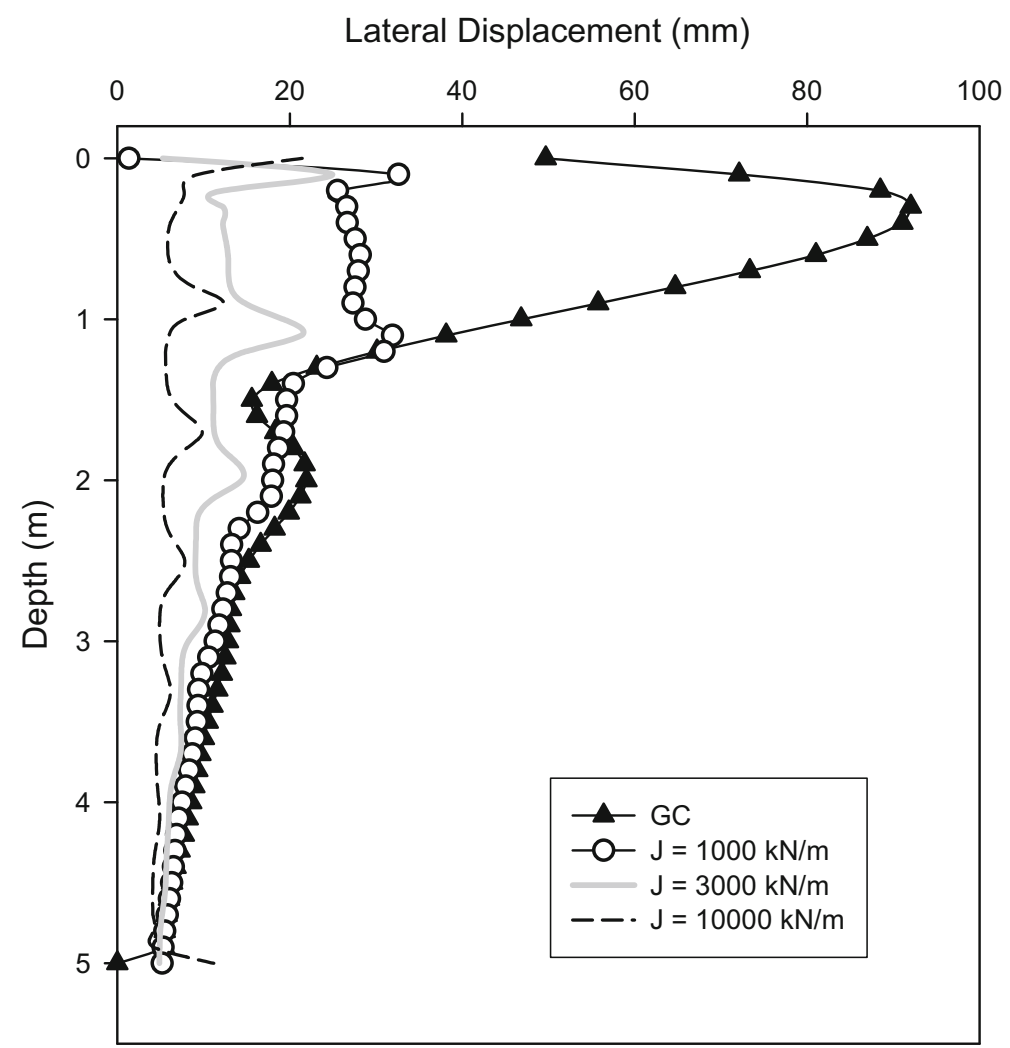

Fig. 8 Effect of encasement stiffness on the lateral displacement of GECs for an embankment height of $5.0 \mathrm{~m}$

analyses (Fig. 10). It is evident that variations in the ARR have a rather pronounced effect on the settlement reduction ratios. It is not surprising that the settlement reduction ratio increases as the ARR decreases. However, it is interesting to note the magnitude of the difference between the values of $\beta$ when the ARR changes from 10 to $30 \%$. In particular, the decrease in $\beta$ as the ARR changes from 10 to $20 \%$ is significantly greater than the decrease in $\beta$ when the ARR changes from 20 to $30 \%$. Comparing Figs. 9 and 10, it is clear that the effect of changes in the ARR is more pronounced on the values of the settlement reduction ratio (Fig. 10) than it is on the values of the vertical stress on the GEC (Fig. 9).

\section{Effect of the Length of Geosynthetic Encasement}

As shown in Fig. 6, significant lateral displacement (bulging) occurs in the top portion of GCs that are used in CSE construction. Hughes and Withers [21] and Madhav and Miura [44] have stated that bulging is the most common failure mode that occurs in the top portion of GCs. Consequently, for GECs used in CSE construction, it may be sufficient to partially encase only the top portion of the column, while still achieving essentially the same performance as for a fully encased column. Several researchers have studied the performance of partially encased columns (e.g., [29, 47, 48, 63-65]). For single GECs, Murugesan and Rajagopal [47, 48] reported the optimum length of 


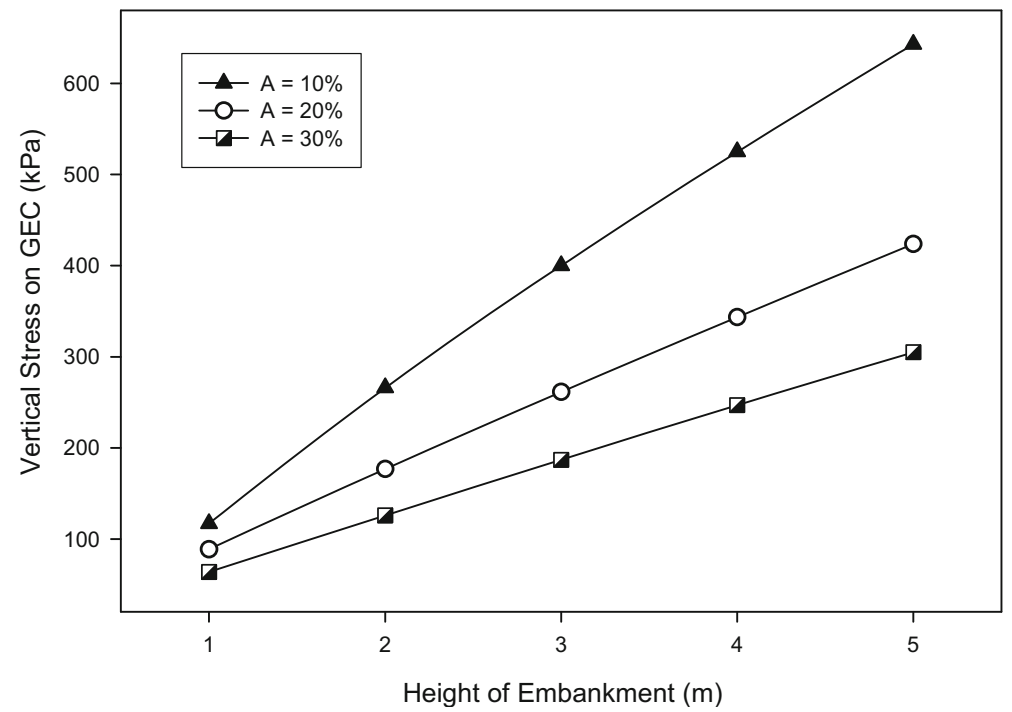

Fig. 9 Effect of area replacement ratio (ARR) on the average stress carried by a GEC

encasement to be $2-4 D$, where $D$ is the diameter of the GEC. Khabbazian et al. [29] concluded that the effectiveness of partially encased columns in achieving the same performance as fully encased columns is related to the level of loads that are applied at the top of the column. For GECs in group configurations (i.e., CSEs), Yoo and Kim [64] suggested that different optimum encasement lengths should be selected for shortand long-term loading. Yoo [63] performed finite element analyses and concluded that the critical encasement length depends strongly on the loading type (i.e., isolated column loading or embankment loading in CSEs). Yoo [63] also stated that full encasement might be required to achieve the maximum settlement reduction when

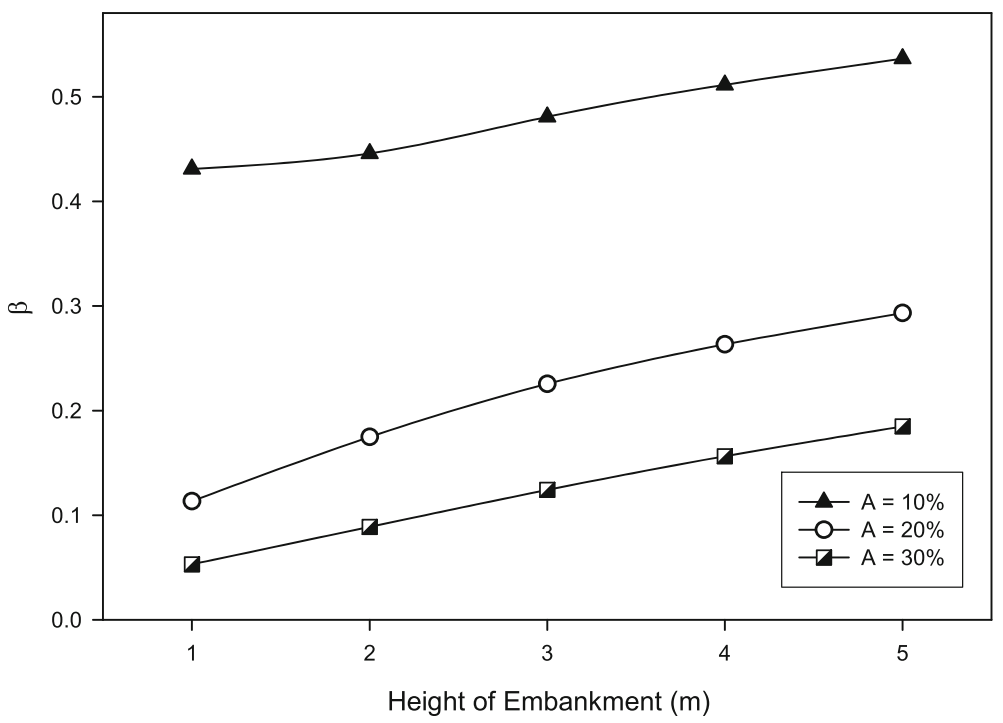

Fig. 10 Effect of area replacement ratio (ARR) on the settlement reduction ratio $(\beta)$ 
using GECs in CSE applications. Yoo and Lee [65] conducted full-scale load tests on a single GEC and found that the critical encasement length of geogrid was 2$3 D$ from the ground surface based on the measured hoop strains and recommended to encase at least the top $4 D$ of the column to maximize the improvement from the encasement.

To investigate the influence that the length of geosynthetic encasement in the GECs has on the performance of CSEs, finite element analyses were performed with the length of the GEC encasement varying from $0.8 \mathrm{~m}(1 D)$ to $5.0 \mathrm{~m}$ (fully encased). In these analyses, all other parameters were maintained at their "base" values. Figure 11 shows the vertical stresses that are transferred to the GECs with varying lengths of encasement as a function of embankment height. For comparison, the vertical stresses transferred to a $\mathrm{GC}$ are also shown in this figure. From Fig. 11, it is clear that the load carried by partially encased columns with a length of encasement of $2 D$ or greater is equal to the load carried by a fully encased column. In other words, except for the partially encased GECs with a length of encasement equal to $1 D$, the portion of the embankment load that is transferred to the GEC is independent of the length of encasement. Figure 11 also shows that encasing a $\mathrm{GC}$, even to a depth of $1 D$, can significantly increase the embankment load that is transferred to the column.

From the results presented in Fig. 11, one could incorrectly infer that the performance of a partially encased GEC with a length of encasement of $2 D$ or greater is exactly the same as for a fully encased column. However, both the load carried by a GEC and its vertical settlement must also be taken into consideration. To better understand the performance of partially encased GECs that are used in CSE applications, the stresses transferred to the GEC versus its vertical displacement under the applied vertical stress are shown in Fig. 12 for embankment heights varying from 1.0 to $5.0 \mathrm{~m}$. For clarity, at the same height of embankment, points representing the vertical displacement of GECs (with varying length of encasement) at the corresponding

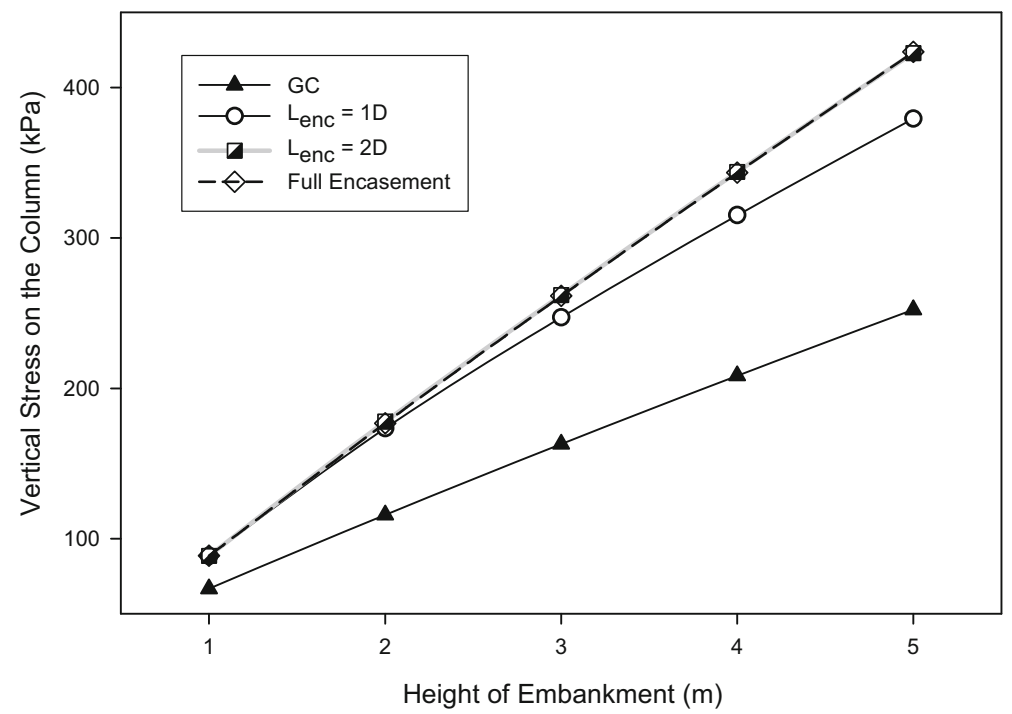

Fig. 11 Effect of length of encasement on the average stress at the top of a GEC 
vertical stress levels are connected to each other with dashed lines. As shown, for an embankment height of $1.0 \mathrm{~m}$, the stresses carried by the GECs and their corresponding settlements are independent of the length of encasement. However, for a GC at an embankment height of $1.0 \mathrm{~m}$, less stress is transferred to the column, yet the column still exhibits greater vertical displacement. As the height of the embankment increases, even though the stress transferred to the partially encased GECs with a length of encasement greater than $1 D$ is the same, the settlement of the GECs increases as the length of encasement decreases. This difference between the vertical displacements of GECs with varying lengths of encasement increases with the height of the embankment. As a result, there is no unique value for the optimum length of encasement for achieving the same performance as fully encased granular columns. In other words, when GECs are used in CSE applications, the optimum length for the encasement is primarily dependent on the serviceability criterion (i.e., allowable vertical settlement) and, to a lesser degree, on the height of the embankment.

Figures 13 and 14 show the lateral displacement of partially encased GECs (with lengths of encasement equal to $1 D, 2 D$, and $3 D$ ), a fully encased column, and a GC for embankment heights equal to 1.0 and $5.0 \mathrm{~m}$, respectively. For an embankment height of $1.0 \mathrm{~m}$, the maximum lateral displacement of GECs with a length of encasement of $1 D$, $2 D$, or $3 D$ is equal to that for a fully encased column. At this height, however, a GC experiences significantly greater values of lateral displacement than the GECs. When the height of the embankment equals $5.0 \mathrm{~m}$, the maximum value of lateral displacement decreases as the length of encasement increases from $1 D$ to $3 D$. However, after an encasement length of $3 D$, additional increases in the length of encasement do not change the maximum lateral displacement. From Figs. 13 and 14, it is clear that encasement of GCs, even up to a depth of $1 D$, can considerably decrease their maximum lateral displacement.

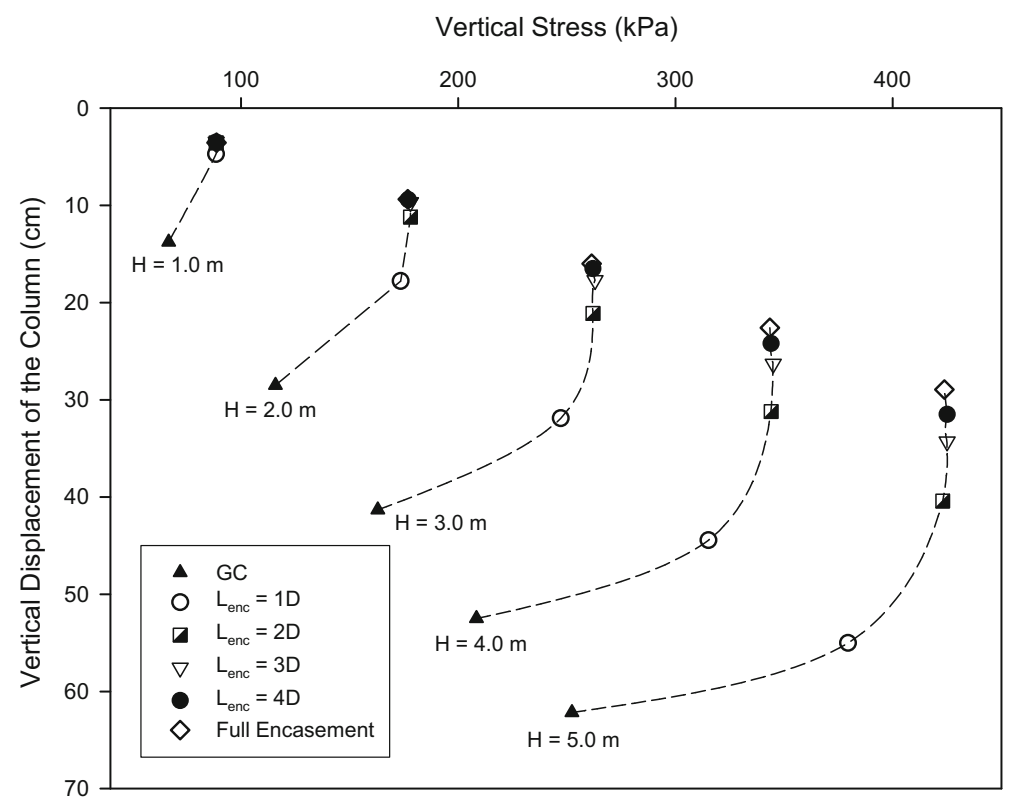

Fig. 12 Effect of length of encasement on the performance of CSEs 


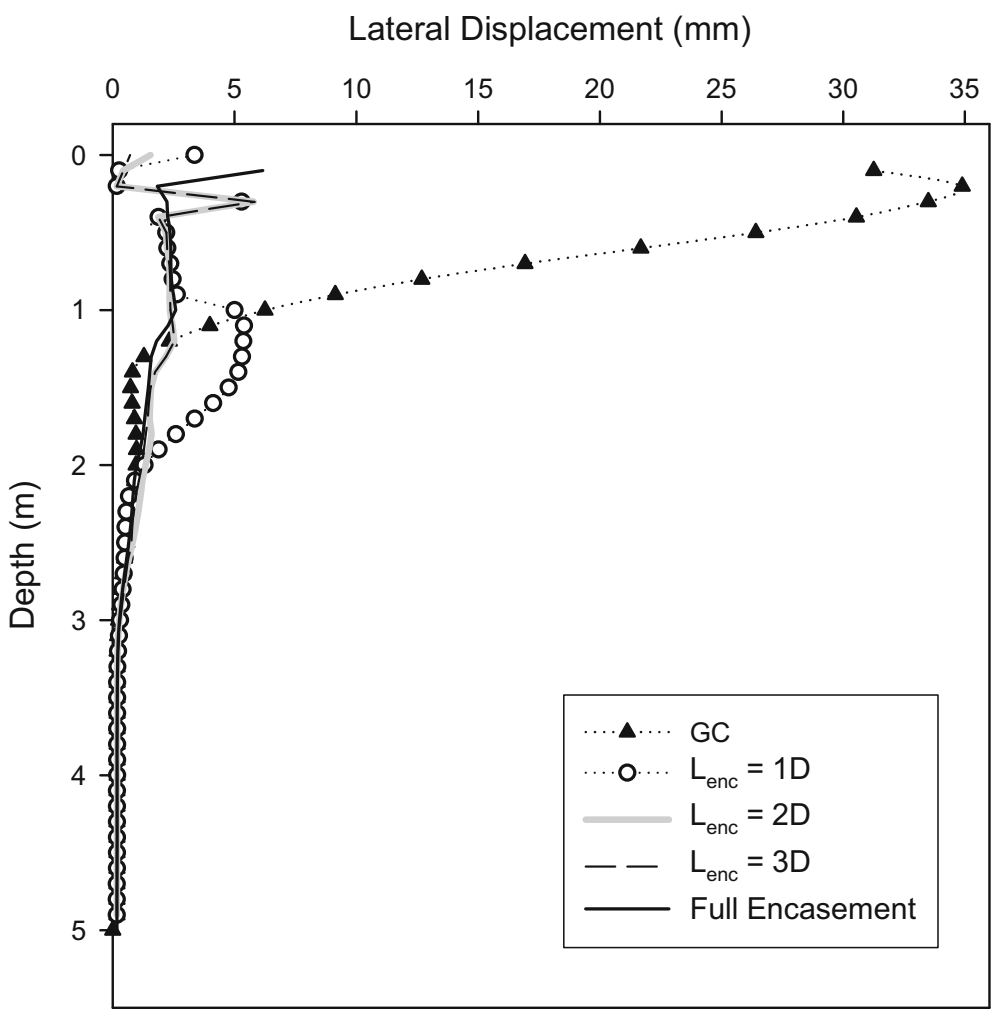

Fig. 13 Effect of length of encasement on the lateral displacement of a column, for a CSE with a height equal to $1.0 \mathrm{~m}$

\section{Effect of Encased Granular Soil Constitutive Model on the Lateral Displacement of GECs}

Kaliakin et al. [24] and Khabbazian et al. [31] studied the influence of the granular soil constitutive model on the performance of GECs. They concluded that it is of utmost importance to accurately characterize the volume change that occurs within the encased granular soil when numerically modeling the stress-displacement response of GECs. For dense encased granular soils, they found that it is very important to properly account for soil dilation that occurs during shear. This can best be done by using an advanced constitutive model, such as the Single Hardening model [34, 37], to characterize the encased granular soil. In contrast, for loose column materials, the particular constitutive model that was used to characterize the behavior of the encased granular soil did not show a significant effect on the simulated behavior of the GEC.

Since the influence of the encased granular soil constitutive model on the behavior of GECs has been comprehensively studied before, it is not repeated herein. Instead, the effect of this model on the lateral displacement of GECs is investigated.

As shown in Figs. 6, 8, 13, and 14, the predicted lateral displacement of a GEC typically does not vary smoothly with depth. Other researchers (e.g., [5, 12, 46, 51, 64]) have also reported this somewhat oscillatory lateral displacement response when modeling the lateral displacement behavior of GECs. Castro and Sagaseta [12] attributed the fluctuations that occur in the lateral displacement to shear bands that develop within the column when a 


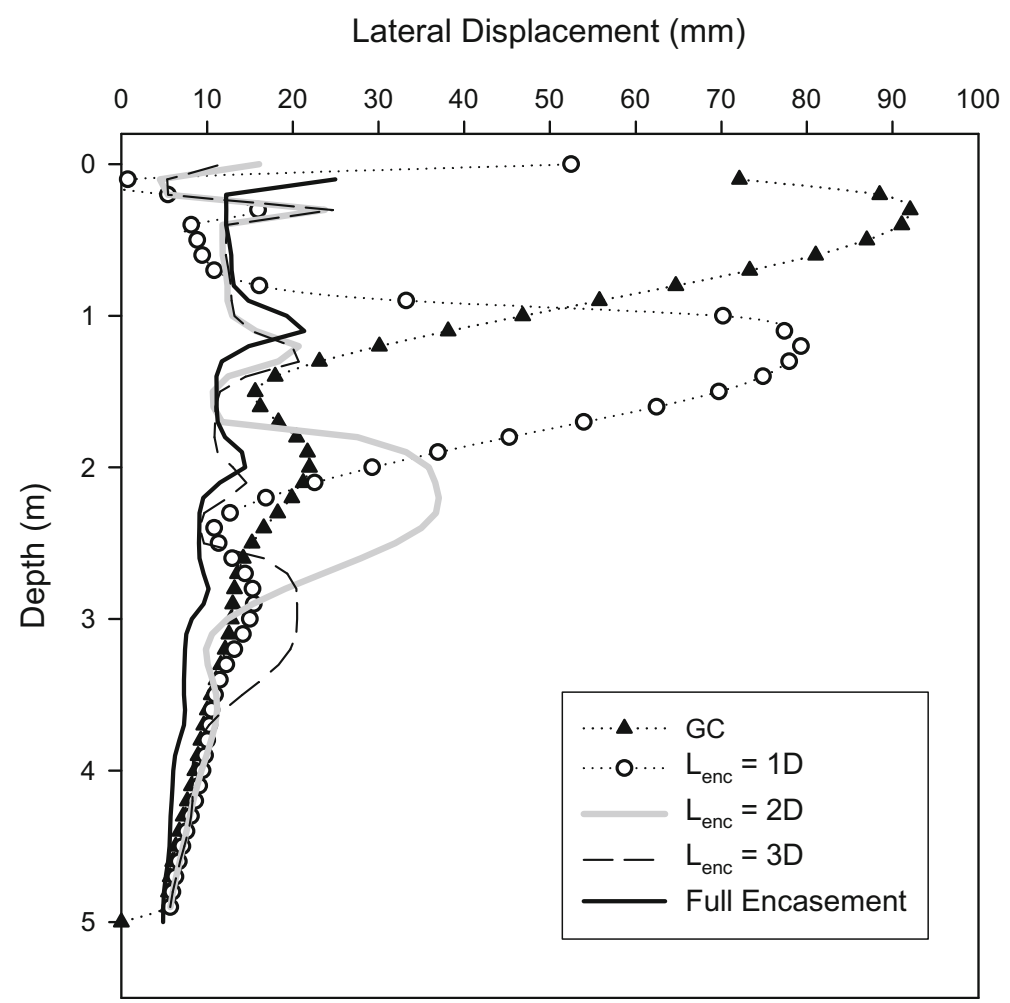

Fig. 14 Effect of length of encasement on the lateral displacement of a column, for a CSE with a height equal to $5.0 \mathrm{~m}$

GEC yields under the applied load. Pulko et al. [51] stated that the variation of the lateral bulging of GECs is a consequence of column yield and strain localization in the finite element analyses. Almeida et al. [5] associated the variation of tensile forces along the length of a GEC to the behavior of dilating zones in triaxial specimens.

To examine the sensitivity of the lateral displacement of GECs to the constitutive model that is used to predict their behavior, analyses were performed using the Mohr-Coulomb and Single Hardening constitutive models to simulate the behavior of the encased granular soil. The Mohr-Coulomb model was selected since all previous researchers that have modeled the performance of CSE systems with GECs have elected to use this constitutive model for the encased granular soil; also, it is the most commonly utilized material model for granular soils in geotechnical engineering. The Single Hardening model was selected based on the findings of Kaliakin et al. [24] and Khabbazian et al. [32], who both showed that more accurate numerical simulations of experimental data for triaxial tests on granular soils could be obtained using this more advanced constitutive model.

The Single Hardening model $[34,37]$ is a rate-independent, work-hardening and softening elastoplastic model that is capable of simulating the behavior of different types of geomaterials subjected to a variety of loading conditions. For materials without cohesion, 11 parameters are associated with the model. The values of these parameters can be determined by matching the results of an isotropic compression test and three drained triaxial tests performed at different confining pressures. Isotropic elasticity is assumed in the Single Hardening model. Although $\nu$ is assumed to be constant, the 
elastic modulus is assumed to vary nonlinearly according to a hypoelastic relation [38] that involves the elastic model parameters $M$ and $\lambda$. The failure surface employed in the Single Hardening model was developed based on extensive laboratory results for frictional materials [35]. It is characterized by values of two model parameters $\left(\eta_{1}\right.$ and $m$ ). The model employs a non-associated flow rule. Both the plastic potential [34] and the yield function [37] were developed from the results of laboratory experiments. Both are characterized by the values of two model parameters $\left(\psi_{2}\right.$ and $\mu$ for the plastic potential; $h$ and $\alpha$ for the yield function). The model hardens and softens isotropically. This requires the values of two additional parameters $(C$ and $p)$. Khabbazian et al. [31] provide a more detailed explanation of the Single Hardening model formulation.

The Single Hardening model is not available in ABAQUS [19]. Consequently, the most recent version of the model [22] was incorporated into ABAQUS using a usersupplied material (UMAT) subroutine that was linked with ABAQUS prior to executing the program.

In this section, the "base" model parameter values presented in the Base Configuration section were again used to simulate the behavior of CSEs with GECs. The encased granular soil was again assumed to be loose Sacramento River sand, and its behavior was simulated with both the Mohr-Coulomb and Single Hardening models. The Single Hardening model parameter values for Sacramento River sand given by Lade [36] were used in the numerical analyses (i.e., $\nu=0.20, M=510, \lambda=0.28, \eta_{1}=28$, $m=0.093, C=1.27 \times 10^{-4}, p=1.65, \psi_{2}=-3.72, \mu=2.36, h=0.534$, and $\left.\alpha=0.794\right)$. Kaliakin et al. [24] provide further details pertaining to the calibration of the MohrCoulomb and Single Hardening model parameter values for Sacramento River sand.

Figure 15 shows the effect of constitutive model selection for simulating the behavior of the encased granular soil on the average vertical stress that is carried by a GEC that is used in CSE construction. As evident from this figure, the vertical stress carried by the GECs is independent of the model that is used to simulate the behavior of the encased granular material. This is in agreement with the findings of Kaliakin et al.

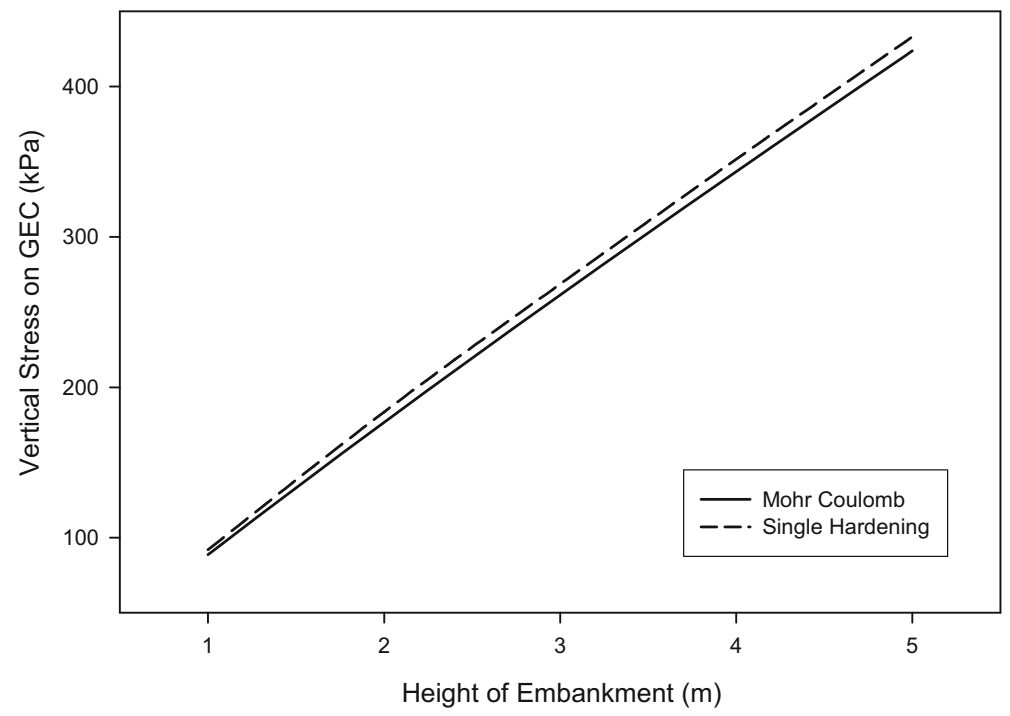

Fig. 15 Effect of encased granular constitutive model on average vertical stress carried by a GEC 
[24], which showed that the constitutive model that is used to characterize the encased granular soil did not have a significant effect on the simulated behavior of a GEC for the case of a loose sand.

Figure 16 shows the lateral displacements of a GEC for an embankment height of $5.0 \mathrm{~m}$ that are predicted by both encased granular soil constitutive models. From this figure, it is evident that the oscillations in the variation of lateral displacement of GECs that are usually observed when the encased granular soil is characterized by the MohrCoulomb model disappear when the same soil is characterized by the Single Hardening model. It is also interesting to note that even though the same value of vertical stress is transferred to the GECs, the maximum lateral displacement predicted by the MohrCoulomb model is $50 \%$ greater than the maximum value calculated using the Single Hardening model. Since the mobilized hoop stresses in the geosynthetic encasement are directly related to the lateral displacement of the GEC, the Mohr-Coulomb model significantly overestimates the maximum value of hoop stresses in the encasement when compared to the results of the Single Hardening model.

More importantly, whereas the distribution of lateral displacements predicted by the Single Hardening model is smooth, the results predicted by the Mohr-Coulomb model exhibit a more oscillatory response. The precise reason for this lack of smoothness in the Mohr-Coulomb model results is not known; however, it is clear that these results are an artifact of the constitutive model, and are not representative of real column behavior. The following observations are pertinent to this conclusion: The mesh, applied loading, and

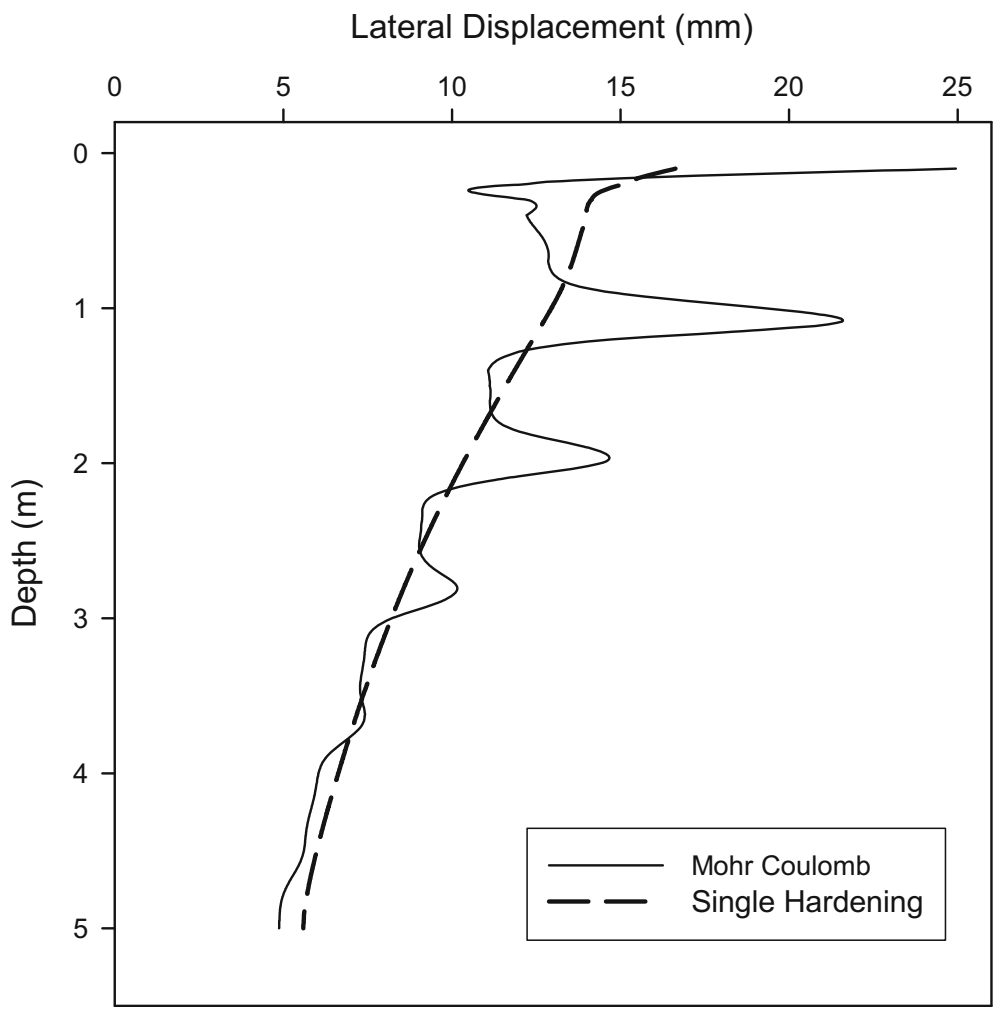

Fig. 16 Effect of encased granular constitutive model on the lateral displacement of a GEC 
nodal specifications remain unchanged in the aforementioned analyses. In addition, both of the models under consideration are elastoplastic in nature, and both use a nonassociative flow rule. Where the models differ is in the analytical definition of elastic modulus (i.e., a constant elastic modulus in the Mohr-Coulomb model and a variable elastic modulus in the Single Hardening model), the shape of their respective failure surfaces and plastic potentials, and in the algorithms used in their numerical implementation within ABAQUS [19]. Since specific details pertaining to the implementation of the Mohr-Coulomb model in ABAQUS are not available, a more detailed conclusion about the root cause of this numerical discrepancy could not be drawn.

\section{Conclusions}

This paper has presented the results of three-dimensional unit cell finite element analyses that were carried out to investigate the relative importance of different factors affecting the behavior of CSEs when GECs are used as the deep foundation elements. Analyses were first performed to study the influence of geosynthetic encasement on the behavior of GCs in CSEs. Parametric analyses were then carried out to study the effect of the stiffness of the geosynthetic encasement, the area replacement ratio, and the length of geosynthetic encasement on the performance of CSEs. Finally, the sensitivity of the numerical results to the constitutive model that was used to simulate the behavior of the granular column material was examined, with a particular focus on the lateral displacement behavior of the GECs. The following conclusions were reached based on the results of the finite element analyses that were performed:

- Encasing a GC improves the performance of the CSE by significantly increasing the embankment loads that are transferred to the column and reducing both the SRR and the settlement reduction ratio. Encasement also enhances the behavior of the GC by substantially reducing its lateral displacement into the soft surrounding foundation soil.

- No agreement was found between the calculated values of the SRR from finite element analyses and those from ten existing analytical solutions. For GECs, the analytical solutions tended to considerably overestimate the value of the SRR. In the case of GCs, these solutions significantly underestimated the value of the SRR.

- Increasing the stiffness of the geosynthetic encasement in GECs can significantly improve the performance of CSEs. Increases in the encasement stiffness increase the embankment loads transferred to the GECs and reduce the vertical displacements. Although using a stiffer encasement increases the embankment loads transferred to the GEC, it also reduces the lateral displacement of the column.

- As the area replacement ratio increases, both the loads carried by the GECs and the settlement reduction ratio of the CSEs decrease.

- For partially encased GECs with a length of encasement greater than or equal to $2 D$ (where $D$ is the diameter of the GEC), the embankment load transferred to the GEC is independent of the length of encasement. Even though the loads carried by partially encased GECs with a length of encasement greater than or equal to $2 \mathrm{D}$ were equal, increasing the length of the encasement further decreased the values of maximum vertical displacement. This difference in the values of maximum vertical displacement became more pronounced as the height of embankment increased. The same trend 
was also found for the lateral displacement of the GECs. In particular, except at lower embankment heights, higher values of lateral displacement were calculated for GECs with shorter length of encasement. As a result, it is concluded that the suitability of partially encased columns is related to the limitations in vertical and lateral displacements, rather than to the loads carried by the GECs.

- It has been reported by other researchers who used the Mohr-Coulomb model to numerically simulate the behavior of GECs that the lateral displacement of GECs (especially in group configurations) can exhibit oscillations along the length of the column. The strange shape of the model-predicted lateral displacement of GECs is sometimes erroneously attributed to the formation of shear bands within the column (e.g., [12]), which in fact cannot be predicted using the Mohr-Coulomb model. More precisely, in granular soils, shear bands typically form in the "post-peak" or softening region. Since the Mohr-Coulomb model exhibits perfect plasticity, it cannot properly account for the formation of shear bands. Numerical results showed that using the Single Hardening model not only solves this problem but also reduces the maximum value of lateral displacement from that calculated using the Mohr-Coulomb model. The precise reason for this lack of smoothness is not known. However, the mesh, applied loading, and nodal specifications remained unchanged in the aforementioned analyses. In addition, both of the models under consideration are elastoplastic in nature, and both use a non-associative flow rule. Where the models differ is in the shape of the respective failure surfaces and plastic potentials, and in the algorithms used in their numerical implementation within the ABAQUS computer program [19]. Since specific details pertaining to the implementation of the Mohr-Coulomb model in ABAQUS are not available, more detailed conclusions than these could not be drawn.

Acknowledgments This material is based upon work supported in part by the Geosynthetic Institute under its GSI Fellowship Program. The Single Hardening UMAT routines were provided by Prof. Poul Lade (The Catholic University of America), and his support is gratefully acknowledged.

\section{Appendix}

This appendix summarizes the formulation of ten analytical methods that were used to calculate the value of stress reduction ratio (Table 1). Further detail pertaining to each analytical method is provided by Khabbazian [27]. The following parameters are used throughout this Appendix:

a Column diameter/width or pile cap diameter/width (when there is no pile cap, $a$ denotes the column diameter/width; in the case of a pile with a cap, $a$ denotes the cap diameter or width).

$H \quad$ Height of the embankment

$s \quad$ Center-to-center column/pile cap spacing

$\phi \quad$ Friction angle of the fill material

$\sigma_{\mathrm{p}} \quad$ Vertical stress on top of the column/pile cap

$K_{\mathrm{p}} \quad$ Coefficient of passive earth pressure

$q$ Surcharge applied to the top of the embankment

$\gamma \quad$ Unit weight of the fill material 
Table 1 The functional form of ten analytical methods to calculate stress reduction ratio (SRR)

Method

BS $8006[10]$

Terzaghi $[60]^{\mathrm{a}}$

Adapted Terzaghi $1^{\mathrm{b}}$

Adapted Terzaghi $1^{\mathrm{c}}$

German method $^{\mathrm{d}}$

Guido et al. method [16]

Swedish method

Svano et al. [59]

Low et al. [43]

\section{Functional form}

For $H \leq 1.4(s-a): \mathrm{SRR}=\frac{2 s}{(s+a)\left(s^{2}-a^{2}\right)}\left[s^{2}-a^{2}\left(\frac{\sigma_{p}}{\gamma H+q}\right)\right]$

$H>1.4(s-a): \mathrm{SRR}=\frac{2.8 s \gamma}{(s+a)^{2}(\gamma H+q)}\left[s^{2}-a^{2}\left(\frac{\sigma_{p}}{\gamma H+q}\right)\right]$

Where, $\frac{\sigma_{p}}{\gamma H+q}=\left(\frac{C_{c} a}{H}\right)^{2}$ and $C_{c}=1.5(H / a)-0.07$

$\mathrm{SRR}_{2 D}=\frac{(s-a)}{2 H K \tan \phi}\left(1-e^{-2 K(H /(s-a)) \tan \phi}\right)$

where $K=0.7$

$\mathrm{SRR}_{3 D}=\frac{\left(s^{2}-a^{2}\right)}{4 H a K \tan \phi}\left\{1-\exp \left[\frac{-4 H a K \tan \phi}{\left(s^{2}-a^{2}\right)}\right]\right\}$

where $K=1.0$

$\mathrm{SRR}_{3 D}=\frac{\left(s^{2}-a^{2}\right) \gamma}{4 a(\gamma H+q) K \tan \phi}\left\{1-\exp \left[\frac{-4 H a K(\tan \phi) n}{\left(s^{2}-a^{2}\right)}\right]\right\}+$

$\frac{\gamma(1-n) H+q}{(\gamma H+q)} \exp \left(\frac{-4 H a K(\tan \phi) n}{\left(s^{2}-a^{2}\right)}\right)$

Where, $K=0.5$

Hewlett and Randolph [18] SRR is the maximum of the following equations:

$$
\begin{aligned}
& \mathrm{SRR}=\left(1-\frac{a}{s}\right)^{2\left(K_{p}-1\right)}\left(1-\frac{2 s\left(K_{p}-1\right)}{\sqrt{2} H\left(2 K_{p}-3\right)}\right)+\left(\frac{2(s-a)\left(K_{p}-1\right)}{\sqrt{2} H\left(2 K_{p}-3\right)}\right) \\
& \mathrm{SRR}=\frac{1}{\left(\frac{2 K_{p}}{K_{p}+1}\right)\left[\left(1-\frac{a}{s}\right)^{\left(1-K_{p}\right)}-\left(1-\frac{a}{s}\right)\left(1+\frac{a}{s} K_{p}\right)\right]+\left(1-\frac{a^{2}}{s^{2}}\right)}
\end{aligned}
$$

$\mathrm{SRR}=\frac{1}{(1+\lambda)^{X}}+\frac{H_{g}}{H}\left[\frac{1}{\left(1+\frac{\lambda}{4}\right)^{x}}-\frac{1}{(1+\lambda)^{x}}\right]$

Where, $\lambda=\frac{H_{g} \lambda_{2}}{\lambda_{1}}, \lambda_{1}=\frac{1}{8}(s-a)^{2}, \lambda_{2}=\frac{s^{2}+2 s a-a^{2}}{2 s^{2}}$ for $H<s / 2, H_{g}=H$, otherwise $H_{g}=s / 2$

$\mathrm{SRR}=\frac{(s-a) \gamma}{3 \sqrt{2}(\gamma H+q)}$

$\mathrm{SRR}_{2 D}=\frac{(s-a)}{4 H \tan 15^{\circ}}$

$\mathrm{SRR}=\frac{1}{\left(s^{2}-a^{2}\right) H}\left(s^{2} H-\frac{1}{3}\left[\left(a+\frac{2}{\beta} H\right)^{3}-a^{3}\right] \frac{\beta}{2}\right)$

$\mathrm{SRR}=\frac{\alpha}{H}\left\{\frac{\left(K_{p}-1\right)(1-\delta) s}{2\left(K_{p}-2\right)}+(1-\delta)^{K_{p}-1}\left[H-\frac{s}{2}-\frac{s}{2\left(K_{p}-2\right)}\right]\right\}$

Where $\delta=a / s$ and $\alpha=0.8$

\footnotetext{
${ }^{\text {a }}$ Functional form presented by Yun-min et al. [66]

${ }^{\mathrm{b}}$ Functional form presented by Russell and Pierpoint [54]

${ }^{\mathrm{c}}$ Functional form presented by Russell et al. [55]

${ }^{\mathrm{d}}$ Described by Kempfert et al. [25]

${ }^{\mathrm{e}}$ Functional form presented by Russell and Pierpoint [54]

${ }^{\mathrm{f}}$ Presented by Carlson [11] in Swedish and discussed in English by Rogbeck et al. [53] and Horgan and Sarsby [20]
} 


\section{References}

1. Aboshi, H., Ichimoto, E., Enoki, M., Harada, K.: The composer-a method to improve characteristics of soft clay by inclusion of large diameter sand columns. Proceedings of the International Conference on Soil Reinforcement: Reinforced Earth and other Techniques, Paris, vol. 1, pp. 211-216 (1979)

2. Alexiew, D., Brokemper, D., Lothspeich, S.: Geotextile encased columns (GEC): load capacity, geotextile selection and pre-design graphs. Proceeding of the Geo-Frontiers 2005 Congress, Austin, Texas, pp. 1-14 (2005)

3. Ali, K., Shahu, J.T., Sharma, K.G.: Model tests on geosynthetic-reinforced stone columns: a comparative study. Geosynth. Int. 19(4), 292-305 (2012)

4. Al-Joulani, N., Bauer, G.E.: Laboratory behavior of sleeve-reinforced stone columns. Geosynthetics ' 95 Conference Proceedings, pp. 1111-1123 (1995)

5. Almeida, M.S.S., Hosseinpour, I., Riccio, M.: Performance of a geosynthetic encased column (GEC) in soft ground: numerical and analytical studies. Geosynth. Int. 20(4), 252-262 (2013)

6. Ayadat, T., Hanna, A.M.: Encapsulated stone columns as a soil improvement technique for collapsible soil. Ground Improv. 9(4), 137-147 (2005)

7. Balasubramanian, A.S., Chaudhry, A.R.: Deformation and strength characteristics of soft Bangkok clay. J. Geotech. Eng. Div. ASCE 104(9), 1153-1167 (1978)

8. Bergado, D.T.: Improvement Techniques of Soft Ground in Subsiding and Lowland Environment, p. 222. Taylor \& Francis, Boca Raton (1994)

9. Brooker, E.W., Ireland, H.O.: Earth pressures at rest related to stress history. Can. Geotech. J. 2(1), 1-15 (1965)

10. BS 8006: Code of Practice for Strengthened/Reinforced Soils and Other Fills. BSI, Milton Keynes (1995)

11. Carlson, B.O.: Armerad Jord beräkningsprinciper för banker på pålar. Terranova, Distr. SGI, Linköping (1987). in Swedish

12. Castro, J., Sagaseta, C.: Consolidation around stone columns. Influence of column deformation. Int. J. Numer. Anal. Methods Geomech. 33(7), 851-877 (2009)

13. Collin, J.G.: Column supported embankment design considerations. In: Labuz, J.F., Bentler, J.G. (eds.) Proceedings of the 52nd Annual Geotechnical Engineering Conference, pp. 51-78. University of Minnesota, St. Paul (2004)

14. Elsawy, M.B.D.: Behaviour of soft ground improved by conventional and geogrid-encased stone columns, based on FEM study. Geosynth. Int. 20(4), 276-285 (2013)

15. Gniel, J., Bouazza, A.: Improvement of soft soils using geogrid encased stone columns. Geotext. Geomembr. 27(3), 167-175 (2009)

16. Guido, V.A., Knueppel, J.D., Sweeny, M.A.: Plate loading tests on geogrid-reinforced earth slabs. Geosynthetic '87 Conference New Orleans, pp. 216-25 (1987)

17. Han, J., Collin, J.G., Huang, J.: Recent development of geosynthetic-reinforced column-supported embankments. Proceedings of the 55th Highway Geology Symposium, Kansas City, Missouri, September 7-10, pp. 299-321 (2004)

18. Hewlett, W.J., Randolph, M.F.: Analysis of piled embankments. Ground Eng. (Lond. Engl.) 21(3), 12-18 (1988)

19. Hibbitt, Karlsson and Sorensen Inc.: ABAQUS User's Manual, Version 6.7, Pawtucket, R.I. (2007)

20. Horgan, G.J., Sarsby, K.W.: The arching effect of soils over voids and piles incorporating geosynthetic reinforcement. Proceedings of the 7th International Conference on Geosynthetics, Nice, pp. 373-378 (2002)

21. Hughes, J.M.O., Withers, N.J.: Reinforcing of soft cohesive soils with stone columns. Ground Eng. 7(3), 42-49 (1974)

22. Jakobsen, K.P., Lade, P.V.: Implementation algorithm for a Single Hardening constitutive model for frictional materials. Int. J. Numer. Anal. Methods Geomech. 26(7), 661-681 (2002)

23. Juran, I., Riccobono, O.: Reinforced soft soils with artificially cemented compacted-sand columns. J. Geotech. Eng. ASCE 117(7), 1042-1060 (1991)

24. Kaliakin, V.N., Khabbazian, M., Meehan, C.L.: Modeling the behavior of geosynthetic encased columns: influence of granular soil constitutive model. Int. J. Geomech. ASCE 12(4), 357-369 (2012). doi:10.1061/ (ASCE)GM.1943-5622.0000084 
25. Kempfert, H.-G., Gobel, C., Alexiew, D., Heitz, C.: German recommendations for reinforced embankments on pile-similar elements. EuroGeo3: 3rd European Geosynthetics Conference, Geotechnical Engineering with Geosynthetics, Munich, pp. 279-284 (2004)

26. Keykhosropur, L., Soroush, A., Imam, R.: 3D numerical analyses of geosynthetic encased stone columns. Geotext. Geomembr. 35(2012), 61-68 (2012)

27. Khabbazian, M.: Numerical simulation of geosynthetic encased columns used individually and in group configurations. A dissertation submitted to the Faculty of the University of Delaware in partial fulfillment of the requirements for the degree of Doctor of Philosophy in Civil Engineering (2011)

28. Khabbazian, M., Kaliakin, V.N., Meehan, C.L.: 3D analyses of geosynthetic encased stone columns. Proc. of International Foundations Congress and Equipment Expo 09 (IFCEE09), Contemporary Topics in Ground Modification, Problem Soils, and Geo-Support, Geotechnical Special Publication No. 187, Orlando, FL, March 15-19, ASCE, pp. 201-208 (2009)

29. Khabbazian, M., Kaliakin, V.N., Meehan, C.L.: Numerical study of the effect of geosynthetic encasement on the behaviour of granular columns. Geosynth. Int. 17(3), 132-143 (2010)

30. Khabbazian, M., Meehan, C.L., Kaliakin, V.N.: Numerical study of effect of encasement on stone column performance. Proc., GeoFlorida 2010: Advances in Analysis, Modeling \& Design, Geotechnical Special Publication No. 199, West Palm Beach, FL, February 20-24, 2010, ASCE, Reston, VA, pp. 184-193 (2010)

31. Khabbazian, M., Kaliakin, V.N., Meehan, C.L.: Performance of quasilinear elastic constitutive models in simulation of geosynthetic encased columns. Comput. Geotech. 38(8), 998-1007 (2011)

32. Khabbazian, M., Meehan, C.L., Kaliakin, V.N.: Influence of granular soil constitutive model when simulating the behavior of geosynthetic encased columns. Geo-Frontiers 2011: Advances in Geotechnical Engineering, Geotechnical Special Publication No. 211, Dallas, TX, March 13-16, 2011, ASCE, Reston, VA, pp. 539-548 (2011b)

33. Khabbazian, M., Kaliakin, V.N., Meehan, C.L.: "Numerical simulation of column supported embankments with geosynthetic encased columns: influence of soft soil constitutive model." Geo-Congress 2012: State of the Art and Practice in Geotechnical Engineering, Oakland, CA, March 25-29, ASCE, pp. 1-10 (2012)

34. Kim, M.K., Lade, P.V.: Single hardening constitutive model for frictional materials, I. Plastic potential function. Comput. Geotech. 5(3), 307-324 (1988)

35. Lade, P.V.: Elasto-plastic stress-strain theory for cohesionless soil with curved yield surfaces. Int. J. Solids Struct. 13(11), 1019-1035 (1977)

36. Lade, P.V.: Single hardening model for soils: parameter determination and typical values. In: Yamamuro, J.A., Kaliakin, V.N. (eds.) Soils Constitutive Models. Evaluation, Selection, and Calibration, ASCE Geotechnical Special Technical Publication 128, pp. 290-309. ASCE, New York (2005)

37. Lade, P.V., Kim, M.K.: Single hardening constitutive model for frictional materials, II. Yield criterion and plastic work contours. Comput. Geotech. 6(1), 13-29 (1988)

38. Lade, P.V., Nelson, R.B.: Modelling the elastic behaviour of granular materials. Int. J. Numer. Anal. Methods Geomech. 11(5), 521-542 (1987)

39. Lee, K.L., Seed, H.B.: Drained strength characteristics of sands. J. Soil Mech. Found. Div. ASCE 93(6), 117-141 (1967)

40. Lee, D., Yoo, C., Park, S.: Model tests for analysis of load carrying capacity of geogrid encased stone column. Proceeding of the Seventeenth International Offshore and Polar Engineering Conference, Lisbon, Portugal, July 1-6, pp. 1632-1635 (2007)

41. Liu, H.L., Ng, C.W.W., Fei, K.: Performance of a geogrid-reinforced and pile supported highway embankment over soft clay: case study. J. Geotech. Geoenviron. 133(12), 1483-1493 (2007)

42. Lo, S.R., Zhang, R., Mak, J.: Geosynthetic-encased stone columns in soft clay: a numerical study. Geotext. Geomembr. 28(3), 292-302 (2010)

43. Low, B.K., Tang, S.K., Choa, V.: Arching in piled embankments. J. Geotech. Eng. 120(11), 1917-1938 (1994)

44. Madhav, M.R., Miura, N.: Soil improvement Panel report on stone columns. Proceedings of the 13th International Conference on Soil Mechanics and Foundation Engineering, New Delhi, India, Vol. 5, pp. 163-164 (1994)

45. Malarvizhi, S.N., Ilamparuthi, K.: Load versus settlement of clay bed stabilized with stone and reinforced stone columns. Proceedings of GeoAsia-2004, Seoul, Korea, pp. 322-329 (2004)

46. Malarvizhi, S.N., Ilamparuthi, K.: Performance of stone column encased with geogrids. Proceedings of the 4th International Conference on Soft Soil Engineering, pp. 309-314 (2007)

47. Murugesan, S., Rajagopal, K.: Geosynthetic-encased stone columns: numerical evaluation. Geotext. Geomembr. 24(6), 349-358 (2006) 
48. Murugesan, S., Rajagopal, K.: Model tests on geosynthetic-encased stone columns. Geosynth. Int. 14(6), 346-354 (2007)

49. Naughton, P.J., Kempton, G.T.: Comparison of analytical and numerical analysis design methods for piled embankments. Contemporary Issues in Foundation Engineering, ASCE Geotechnical Special Publication 131, pp. 135-144 (2005)

50. Park, S., Yoo, C., Lee, D.: A study on the geogrid reinforced stone column system for settlement reduction effect. Proceedings of the Seventeenth International Offshore and Polar Engineering Conference, Lisbon, Portugal, July 1-6, pp. 1636-1641 (2007)

51. Pulko, B., Majes, B., Logar, J.: Geosynthetic-encased stone columns: analytical calculation model. Geotext. Geomembr. 29(1), 29-39 (2011)

52. Rao, B.G., Bhandari, R.K.: Skirting - a new concept in design of heavy storage tank foundation. Proceedings of the 6th South-East Conference on soil Engineering, Taipei, Taiwan, pp. 283-300 (1980)

53. Rogbeck, Y., Gustavsson, S., Sodergren, I., Lindquist, D.: Reinforced piled embankments in Sweden: design aspects. Proceedings of the 6th International Conference on Geosynthetics, pp. 755-762 (1998)

54. Russell, D., Pierpoint, N.: An assessment of design methods for piled embankments. Ground Eng. 30(11), 39-44 (1997)

55. Russell, D., Naughton, P.J., Kempton, G.: A new design procedure for piled embankments. Proceedings of the 56th Canadian Geotechnical Conference and the NAGS Conference, Winnipeg, MB, pp. 858-865 (2003)

56. Sharma, R.S., Kumar, B.R.P., Nagendra, G.: Compressive load response of granular piles reinforced with geogrids. Can. Geotech. J. 41(1), 187-192 (2004)

57. Sivakumar, V., McKelvey, D., Graham, J., Hughes, D.: Triaxial tests on model sand columns in clay. Can. Geotech. J. 41(2), 299-312 (2004)

58. Stewart, M.E., Filz, G.M.: Influence of clay compressibility on geosynthetic loads in bridging layers for column-supported embankments. Contemporary Issues in Foundation Engineering, ASCE Geotechnical Special Publication 131, pp. 96-109 (2005)

59. Svano, G., Ilstad, T., Eiksund, G., Want, A.: Alternative calculation principle for design of piled embankments with base reinforcement. Proceeding of 4th International Conference on Ground Improvement Geosystems, Helsinki, Finland (2000)

60. Terzaghi, K.: Theoretical Soil Mechanics. Wiley, New York (1943)

61. Trunk, G., Heerten, A., Poul, A., Reuter, E.: Geogrid wrapped vibro stone columns. EuroGeo 3, 289-294 (2004)

62. Wu, C.S., Hong, Y.S.: Laboratory tests on geosynthetic-encapsulated sand columns. Geotext. Geomembr. 27(2), 107-120 (2009)

63. Yoo, C.: Performance of geosynthetic-encased stone columns in embankment construction: numerical investigation. J. Geotech. Geoenviron. 136(8), 1148-1160 (2010)

64. Yoo, C., Kim, S.B.: Numerical modeling of geosynthetic-encased stone column-reinforced ground. Geosynth. Int. 16(3), 116-126 (2009)

65. Yoo, C., Lee, D.: Performance of geogrid-encased stone columns in soft ground: full-scale load tests. Geosynth. Int. 19(6), 480-490 (2012)

66. Yun-min, C., Wei-ping, C., Ren-peng, C.: An experimental investigation of soil arching within basal reinforced and unreinforced piled embankments. Geotext. Geomembr. 26(2), 164-174 (2008) 